\title{
Camellia oleifera Shell as a Potential Agricultural By-product for Paper Production
}

\author{
Wenhua Gao, ${ }^{\mathrm{a}, \mathrm{b}}$ Luyao Huang, ${ }^{\mathrm{b}}$ Zhihui Lei, ${ }^{\mathrm{b}}$ and Zhiwei Wang ${ }^{\mathrm{a}, *}$ \\ The aim of this study was to investigate a potential biorefinery process to \\ realize the high utilization of Camellia oleifera shell (COS), which is an \\ agricultural by-product mainly composed of cellulose, hemicellulose, and \\ lignin. Before treatment by steam explosion, the COS was impregnated \\ with water, 3.0 wt $\% \mathrm{NaOH}$ solution, or $3.0 \mathrm{wt} \% \mathrm{H}_{2} \mathrm{SO}_{4}$ solution. The \\ morphological structure and chemical composition of the steam-exploded \\ COS pulp were investigated. The results indicated that the impregnation \\ treatments increased the cellulose content of the steam-exploded COS \\ pulp and decreased the hemicellulose and lignin content. The morphology \\ of steam-exploded COS fiber was short, coarse and stiff. Hydrophobic and \\ colorful handsheets were fabricated by mixing proportional bleached \\ softwood fiber. This study demonstrated that COS was a potential material \\ for the papermaking industry, and the combination of water impregnation \\ and steam explosion treatment for COS was a good pulp process.
}

Keywords: Camellia oleifera shell; Impregnation; Steam explosion; Fiber

Contact information: a: Guangxi Key Laboratory of Clean Pulp \& Papermaking and Pollution Control, College of Light Industry and Food Engineering, Guangxi University, Nanning, CN 530004 China; b: State Key Laboratory of Pulp and Paper Engineering, South China University of Technology, Guangzhou, CN 510640 China; *Corresponding author: wangzhiwei@gxu.edu.cn

\section{INTRODUCTION}

Camellia oleifera is one of the important oil woody species distributed especially in Southern China, with a total planting area around $3.5 \times 10^{6} \mathrm{hm}^{2}$ and an annual yield of approximately 560 million tons (Lei et al. 2019). Camellia oleifera shell (COS) is a byproduct produced in the manufacture process of Camellia oleifera oil, accounting for 50 60\% of the whole Camellia oleifera fruit by weight (Zhu et al. 2013). This means that in the process of Camellia oleifera oil production, 1 ton of Camellia oleifera fruit can produce about 0.54 tons of COS. Generally, the COS is discarded or burnt as agricultural waste. Therefore, the comprehensive utilization of the renewable COS has become an unavoidable issue. It is noteworthy that COS is a type of lignocellulosic biomass and mainly consists of cellulose, hemicellulose, and lignin, where the compact structure of the cellulose fibers and hemicellulose components are embedded in the wall of lignin (Yao et al. 2017). To realize the biorefinery of COS, the complex structure of the COS cell wall needs to be broken down.

Steam explosion is a type of technology developed based on traditional pulping methods and is widely used in deconstructing non-wood biomass due to its unique properties such as low pollution loading, high pulping yield, low energy consumption, low cost, and good controllability (Duangwang et al. 2016). It has been demonstrated that the steam explosion treatment is effective for the removal of lignin and hemicellulose from biomass and improving the cellulose digestibility of plant materials such as corn stover, 
cotton stalk, kenaf bast, oil palm empty fruit bunches, wheat straw, rice straw, bagasse, sisal hemp, etc. (Dong et al. 2014; Duangwang et al. 2016; Carvalho et al. 2018; Song et al. 2018; Shi et al. 2019). In the steam explosion process, the biomass is treated by saturated steam with a high pressure (0.69 to $4.84 \mathrm{MPa})$ and temperature $\left(160\right.$ to $260{ }^{\circ} \mathrm{C}$ ) (Kataria $e t$ al. 2017). A rapid decompression follows, which forces the biomass to break down the cell wall structure, producing many fibers and fiber bundles. During the process, the high temperature and high pressure cause the release of acids from acetylated components in the biomass. These acids can catalyze hydrolytic reactions, resulting in the release of hemicellulose and lignin and expose the cellulosic fibers (Kataria et al. 2017; Santo et al. 2019). It should be noted that water is the only reagent and transfer medium participating in the steam explosion process when no extra chemicals are employed (Sui and Chen 2016). However, during the impregnation stage, chemicals may be needed, and biomass is usually pretreated by acid or alkali to improve the degree of fiber fibrillation and delignification (Sabiha-Hanim et al. 2015; Iram et al. 2019).

In this study, different impregnation treatments of COS before steam explosion pulping are investigated. The COS was first pretreated either with water alone, $\mathrm{NaOH}$ solution, or $\mathrm{H}_{2} \mathrm{SO}_{4}$ solution, and then the impregnated COS was used for steam explosion pulping. The chemical composition and fiber characteristics of the steam-exploded COS pulp were also analyzed. The properties of the steam-exploded COS fibers were indirectly measured by mixing softwood pulp to fabricate biomaterials. This goal of the study was to explore a feasible treatment process for COS to realize the efficient and comprehensive utilization of an agricultural by-product.

\section{EXPERIMENTAL}

\section{Materials}

Camellia oleifera shell was provided by Guangxi Zhuang Autonomous Region Forestry Research Institute (Guangxi, China). After selection, the COS was washed by distilled water and dried at $60{ }^{\circ} \mathrm{C}$. Then, the COS was cut into $0.5 \mathrm{~cm} \times 1.0 \mathrm{~cm}$ pieces. Subsequently, the COS was impregnated with water, $3.0 \mathrm{wt} \% \mathrm{NaOH}$ solution, and $3.0 \mathrm{wt} \%$ $\mathrm{H}_{2} \mathrm{SO}_{4}$ solution at room temperature for $24 \mathrm{~h}$, where the solid-to-liquid ratio was 1:2 $(\mathrm{g}: \mathrm{L})$. The bleached softwood kraft pulp were obtained from a paper mill (Guangdong, China) and treated by a PFI machine (Hamjern Maskin; Hamar, Norway) to achieve a beating degree of $40{ }^{\circ} \mathrm{SR}$ according to TAPPI T248 sp-00 (2000) method. The beating degree of pulp was measured using a Schopper-Riegler tester (mod. 95587 PTI) according to ISO 5267-1 (1999) standard. In addition, all standard chemicals used in this study were of analytical grade.

\section{Steam Explosion Treatment}

The impregnated COS (300 g absolute dry) was treated in a steam jacked reactor $(D=20 \mathrm{~cm}, H=150 \mathrm{~cm}$ ) at a steam pressure of $2.0 \mathrm{MPa}$ with a retention time of $4 \mathrm{~min}$. When the reaction was completed, a sudden reduction of pressure promoted to give the explosion effect and the treated sample was collected. Then, the treated COS was washed with tap water until the $\mathrm{pH}$ of the washing liquid was close to neutral. Afterward, the treated COS was screened by an 8 mesh $(2.36 \mathrm{~mm})$ flat sieve to remove large fiber bundles, and the final obtained COS pulps (EP) were named EP- $\mathrm{H}_{2} \mathrm{O}, \mathrm{EP}-\mathrm{NaOH}$, and $\mathrm{EP}-\mathrm{H}_{2} \mathrm{SO}_{4}$. 


\section{Handsheets Preparation}

The laboratory handsheets $\left(80 \mathrm{~g} / \mathrm{m}^{2}\right)$ were made by mixing exploded pulps and softwood pulps (40 ${ }^{\circ} \mathrm{SR}$ ), where the proportion of exploded pulps was $10 \%, 20 \%, 30 \%$, $40 \%, 50 \%, 60 \%$, and $70 \%(\mathrm{w} / \mathrm{w})$. The mixture was vacuum dewatered in a Rapid Köthen type laboratory sheet former (ISP mod. 786FH) according to ISO 5269-2 (2004). The obtained wet handsheets were pressed at $400 \mathrm{kPa}$ for $5 \mathrm{~min}$ to further remove the excess water and then dried at $95{ }^{\circ} \mathrm{C}$. Finally, the handsheets were conditioned at $23{ }^{\circ} \mathrm{C} \pm 1{ }^{\circ} \mathrm{C}$ and $50 \% \pm 2 \%$ relative humidity $(\mathrm{RH})$ for at least $24 \mathrm{~h}$ before further testing. The handsheets made from pure softwood pulps were named PSP, and the handsheets made from mixing exploded pulps and softwood pulps were named EP-X-Y\% (where X was the type of impregnation and $\mathrm{Y}$ was the proportion of exploded pulps).

\section{Chemical Composition Analysis}

The chemical composition of COS and steam-exploded fibers were tested according to the procedures described previously (Xiang et al. 2014). Firstly, the materials were extracted by toluene/ethanol $(2: 1, \mathrm{v} / \mathrm{v})$, and then the chemical composition of four fibers was determined according to National Renewable Energy Laboratory (NREL) procedures. Sand core crucibles and a UV-visible spectrophotometer (UV-VIS, UV-1900; Shimadzu, Kyoto, Japan) were used to analyze the content of acid-insoluble and soluble lignin. The chemical composition of carbohydrates, including cellulose and hemicellulose, was analyzed by high-performance anion-exchange chromatography (ICS-3000; Thermo Fisher Scientific, Waltham, MA, USA).

\section{Properties of Steam-exploded Fibers}

The fiber length distribution of the exploded pulps was indirectly measured by a Bauer-McNett fiber classifier (Bauer-McNett S401800007; PTI, Frank, Germany). A certain amount of each of the pulps (10.0 $\mathrm{g}$ of the absolute dry weight) was mixed with $1000 \mathrm{~mL}$ water. The fibers successively passed through 16, 30, 50, 100, and 200 mesh sieves in turn, corresponding to $1.0,0.6,0.3,0.15$, and $0.075 \mathrm{~mm}$ sieves. The obtained fibers of each part were collected and dried in an oven until they reached a constant weight. The yield was expressed with the following Eq. 1,

$$
\text { Yield }=\frac{m}{m_{0}} \times 100 \%
$$

where the $m$ is the constant weight $(\mathrm{g})$ of each part and $m_{0}(10.0 \mathrm{~g})$ is the initial absolute dry weight.

The morphology and microstructure of the steam-exploded COS fiber and obtained handsheets were observed by a scanning electron microscope (EVO 18; Zeiss, Oberkochen, Germany). All the samples were coated with Au before testing (C6217-220 7006-8; Ted Pella Inc., Redding, CA, USA).

\section{Physical Properties of Handsheets}

The surface roughness property and 3D surface topography of the handsheets were measured by an optical profilometer (Universal 3D Profilometer; RTEC Instruments, San Jose, CA, USA). The hydrophobicity of the handsheets was determined by measuring the contact angle by an optical contact angle measuring instrument (ZJ-7000; Zhijia, Shenzhen, China). The volume of the water drops (approximately $5 \mu \mathrm{L}$ ) was accurately controlled by a microliter syringe. In addition, the air permeability property of the handsheets was tested 
using an air permeance tester (L\&W, Stockholm, Sweden). The tensile strength and whiteness of the handsheets were measured according to TAPPI T494 om-01 (2001) and TAPPI T562 pm-96 (1996), respectively.

\section{Color of Handsheets}

The color coordinates $\left(L^{*}, a^{*}\right.$, and $\left.b^{*}\right)$ of the handsheets were measured at five randomly selected positions for each sample and for the D-65 illuminant and $2^{\circ}$ observer. The overall difference in color $\left(\Delta E^{*}\right)$ was evaluated with the following Eqs. 2 and 3 (Cruz et al. 2007; Resa et al. 2014),

$$
\begin{aligned}
& \Delta E^{*}=\sqrt{\left(\Delta L^{*}\right)^{2}+\left(\Delta a^{*}\right)^{2}+\left(\Delta b^{*}\right)^{2}} \\
& \Delta L^{*}=L^{*}-L_{0}{ }^{*} ; \Delta a^{*}=a^{*}-a_{0}{ }^{*} ; \Delta b^{*}=b^{*}-b_{0}{ }^{*}
\end{aligned}
$$

where $L_{0} *, a_{0} *$, and $b_{0} *$ were parameters of PSP, and $L^{*}, a^{*}$, and $b^{*}$ were parameters of the handsheets. To minimize the variability between different samples, the individual $L^{*}$, $a^{*}$, and $b^{*}$ values were normalized, and the equations were expressed with the following Eq. 4 (Cruz et al. 2007):

$$
L^{n}=\frac{L^{*}}{L_{0}{ }^{*}} ; a^{n}=\frac{a^{*}}{a_{0}{ }^{*}} ; b^{n}=\frac{b^{*}}{b_{0}{ }^{*}}
$$

\section{RESULTS AND DISCUSSION}

As presented in Table 1, the carbohydrate polysaccharides of COS mainly consisted of arabinose, galactose, glucose, and xylose. The glucose content of COS was only $14.9 \%$, while the xylose was the predominant sugar at approximately $34.6 \%$. Cellulose is a linear polysaccharide consisting of monomeric units of anhydro-D-glucose units, but hemicellulose is a branched polysaccharide comprised of different sugar monomers such as xylose, mannose, galactose, arabinose, and uronic acids (Pasangulapati et al. 2012; Yu et al. 2019). The results of chemical composition indicated that the COS belonged to lignocellulosic materials with low cellulose content and high hemicellulose content. The hemicellulose of COS might consist mainly of L-arabino-(4-O methyglucurono)-D-xylans (Lei et al. 2019). The cellulose, hemicellulose, and lignin contents of COS were calculated as $10.9 \%, 37.8 \%$, and $38.5 \%$, respectively (Table 1), which was similar with the results of Yao et al. (2017). However, the results were different from general non-wood feedstocks, in which the content of cellulose, hemicellulose, and lignin were determined to be $35 \%$ to $50 \%, 17 \%$ to $25 \%$, and $10 \%$ to $23 \%$, respectively (Neves et al. 2016). The lignin content of COS was approximately $38.5 \%$, which was close to the results of Lei et al. (2019) and Yao et al. (2017). The high hemicellulose and lignin contents made the COS not suitable for traditional pulping technologies. In addition, Table 1 shows the chemical composition of the steam-exploded COS fibers. Compared with the raw COS, the glucose content of the steam-exploded COS fibers was enhanced, while the xylose and lignin contents declined, indicating that the steam explosion process was useful for the removal of hemicellulose and lignin. It was noteworthy that the arabinose, xylose, and lignin contents of EP-NaOH and $\mathrm{EP}-\mathrm{H}_{2} \mathrm{SO}_{4}$ were lower than those of $\mathrm{EP}-\mathrm{H}_{2} \mathrm{O}$. This result suggested that the acid/alkali impregnation treatment was more beneficial for the removal of hemicellulose and lignin in steam explosion technology (Han et al. 2018; Iram et al. 2019). Furthermore, the lignin content of EP-NaOH was lower than that of $\mathrm{EP}-\mathrm{H}_{2} \mathrm{SO}_{4}$, meaning that more lignin dissolved 
in the alkali impregnation process (Table 1). This was attributed to the fact that in the acidic pretreatment process, condensation of the COS lignin occurred a certain degree, which was accompanied by a decrease in $\beta-O-4$ linkages (Sannigrahi et al. 2008). The lignin was partly fragmented. As can be seen from Table 1, the fragmented lignin was partly dissolved in the system due to the relatively mild acid treatment conditions. In the case of the alkali treatment, the COS lignin could be converted to hydrophilic and soluble alkali lignin.

Table 1. Analysis of the Chemical Composition of COS and Steam-exploded COS Pulp

\begin{tabular}{|c|c|c|c|c|c|}
\hline Samples & Arabinose (\%) & Galactose (\%) & Glucose (\%) & Xylose (\%) & Lignin (\%) \\
\hline $\mathrm{COS}^{*}$ & $2.2 \pm 0.1$ & $0.7 \pm 0.02$ & $14.9 \pm 0.2$ & $36.4 \pm 0.3$ & $38.5 \pm 0.1$ \\
\hline $\mathrm{EP}-\mathrm{H}_{2} \mathrm{O}$ & $3.1 \pm 0.2$ & $0.8 \pm 0.1$ & $16.7 \pm 0.1$ & $32.8 \pm 0.8$ & $38.1 \pm 0.1$ \\
\hline $\mathrm{EP}-\mathrm{NaOH}$ & $2.8 \pm 0.2$ & $0.7 \pm 0.01$ & $16.9 \pm 0.4$ & $32.3 \pm 0.1$ & $34.2 \pm 0.3$ \\
\hline $\mathrm{EP}-\mathrm{H}_{2} \mathrm{SO}_{4}$ & $2.9 \pm 0.1$ & $0.8 \pm 0.03$ & $17.0 \pm 0.3$ & $31.4 \pm 0.5$ & $36.5 \pm 0.4$ \\
\hline${ }^{*}$ Note: Camellia oleifera shell (COS)
\end{tabular}

The mean length of the steam-exploded COS pulp was reflected by the screening results (Table 2). A bigger screen mesh number for the fiber to pass through resulted in a shorter fiber length. As shown in Table 2, the fibers of the three steam-exploded COS pulps were mainly distributed in the range of 16 to 100 mesh, and the yield of all samples was approximately $90 \%$. Furthermore, the screened fibers were mainly distributed in the range of 30 to 50 mesh, and the yields of $\mathrm{EP}-\mathrm{H}_{2} \mathrm{O}$ and $\mathrm{EP}-\mathrm{NaOH}$ were $31.3 \%$ and $32.3 \%$, respectively, while the yield of $\mathrm{EP}-\mathrm{H}_{2} \mathrm{SO}_{4}$ was up to $50.1 \%$. Therefore, these fibers were characterized as short fibers. Compared with long fibers, short fibers usually have weaker mechanical strength properties such as tensile strength and tear strength (Gao et al. 2012). Hence, it was deduced that the steam-exploded COS pulp can hardly produce high strength paper as the molecular bonding between fibers may be weak and the fibers may have difficultly interweaving together (Yiin et al. 2019).

Table 2. Screening Results of Steam-exploded COS Pulps

\begin{tabular}{|c|c|c|c|c|c|}
\hline \multirow{2}{*}{ Samples } & \multicolumn{5}{|c|}{ Yield (\%) } \\
\cline { 2 - 6 } & $\begin{array}{c}>16 \\
\text { Mesh }\end{array}$ & $\begin{array}{c}16 \text { to } 30 \\
\text { Mesh }\end{array}$ & $\begin{array}{c}30 \text { to } 50 \\
\text { Mesh }\end{array}$ & $\begin{array}{c}50 \text { to } 100 \\
\text { Mesh }\end{array}$ & $\begin{array}{c}100 \text { to } 200 \\
\text { Mesh }\end{array}$ \\
\hline $\mathrm{EP}-\mathrm{H}_{2} \mathrm{O}$ & 9.4 & 27.0 & 31.3 & 16.3 & 3.4 \\
\hline $\mathrm{EP}-\mathrm{NaOH}$ & 2.6 & 22.3 & 36.3 & 20.4 & 4.6 \\
\hline $\mathrm{EP}-\mathrm{H}_{2} \mathrm{SO}_{4}$ & 4.5 & 8.4 & 50.1 & 22.5 & 4.6 \\
\hline
\end{tabular}

Increasing the proportion of the steam-exploded COS pulp resulted in the tensile index of handsheets decreasing, while the air permeability gradually increased (Table 3). When the addition of the steam-exploded COS pulp was 30\%, the tensile index of the handsheets proportion decreased $50 \%$ for all samples (Table 3). The hydrogen bonding strength and bonding area of the fibers were the two main factors affecting the tensile strength of the paper (Sibaly and Jeetah 2017; Yamamoto et al. 2019). The steam-exploded 
COS fibers had a short and oblate structure and a coarse, uneven surface (Fig. 1). The steam-exploded COS fibers were not fibrillated like bleached softwood fibers, so fewer free hydroxyl groups could be exposed to form hydrogen bonds between fibers (Yiin et al. 2019). Therefore, the addition of steam-exploded COS fibers would weaken the bonding strength between softwood fibers and decrease the bonding area. Although the addition of the steam-exploded COS was unfavorable for the strength of handsheets, it was beneficial for increased air permeability.

Table 3. Tensile Index and Air Permeability of the Steam-exploded COS Pulp Based Handsheets

\begin{tabular}{|c|c|c|c|}
\hline \multicolumn{2}{|c|}{ Samples } & $\begin{array}{c}\text { Tensile Index }(\mathrm{N} \times \\
\left.\mathrm{m} \times \mathrm{g}^{-1}\right)\end{array}$ & Air Permeability $\left(\mu \mathrm{m} \times \mathrm{Pa}^{-1} \times \mathrm{s}^{-1}\right)$ \\
\hline \multicolumn{2}{|l|}{$\mathrm{PSP}$ * } & 58.90 & 0.76 \\
\hline \multirow{7}{*}{$\mathrm{EP}-\mathrm{H}_{2} \mathrm{O}-$} & $10 \%$ & 53.24 & 1.35 \\
\hline & $20 \%$ & 41.77 & 7.47 \\
\hline & $30 \%$ & 32.03 & 16.70 \\
\hline & $40 \%$ & 24.83 & 57.73 \\
\hline & $50 \%$ & 25.42 & 50.30 \\
\hline & $60 \%$ & 17.81 & 55.87 \\
\hline & $70 \%$ & 15.11 & 66.23 \\
\hline \multirow{7}{*}{ EP-NaOH- } & $10 \%$ & 48.45 & 3.56 \\
\hline & $20 \%$ & 41.71 & 8.44 \\
\hline & $30 \%$ & 29.29 & 16.53 \\
\hline & $40 \%$ & 23.06 & 33.30 \\
\hline & $50 \%$ & 24.76 & 33.63 \\
\hline & $60 \%$ & 16.00 & 54.22 \\
\hline & $70 \%$ & 13.69 & 78.57 \\
\hline \multirow{7}{*}{$\mathrm{EP}-\mathrm{H}_{2} \mathrm{SO}_{4}-$} & $10 \%$ & 46.55 & 4.08 \\
\hline & $20 \%$ & 36.06 & 14.08 \\
\hline & $30 \%$ & 29.39 & 30.13 \\
\hline & $40 \%$ & 23.00 & 68.57 \\
\hline & $50 \%$ & 23.47 & 72.71 \\
\hline & $60 \%$ & 16.95 & 100 \\
\hline & $70 \%$ & 13.25 & 100 \\
\hline
\end{tabular}

The heterogeneous pore structure of the paper appeared and could be observed clearly in Fig. 1 with the addition of COS fiber. The air permeability of the three handsheets increased when the added proportion of steam-exploded COS was greater than $40 \%$ (Table $3)$.

The impregnation treatment of COS hardly affected the air permeability, and the SEM microstructures (Fig. 2) among the three samples were also not different. The air permeability of the paper was determined by the gaps from the interweaving fibers and the pores in the fibers (Nong et al. 2019). Increasing the addition of short and stiff steamexploded COS pulp resulted in the microstructures of handsheets becoming loose and rough.

The roughness $\left(R_{\mathrm{a}}\right)$ of PSP was $3.68 \mu \mathrm{m}$, while the $R_{\mathrm{a}}$ of $\mathrm{EP}-\mathrm{H}_{2} \mathrm{O}-70 \%$ was up to $22.45 \mu \mathrm{m}$ (Fig. 3). This indicated that many intervals and gaps were created in the handsheets due to the addition of the steam-exploded COS fibers. 


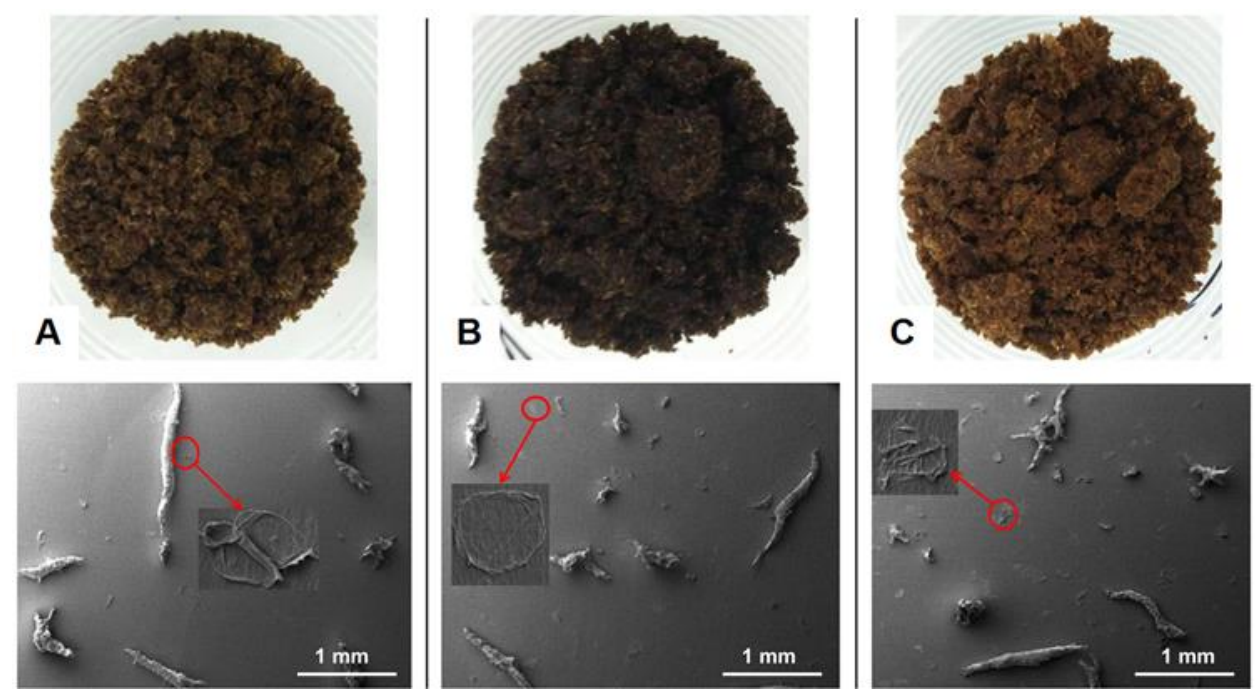

Fig. 1. The morphology of (a) EP- $\mathrm{H}_{2} \mathrm{O}$, (b) $\mathrm{EP}-\mathrm{NaOH}$, and (c) $\mathrm{EP}-\mathrm{H}_{2} \mathrm{SO}_{4}$
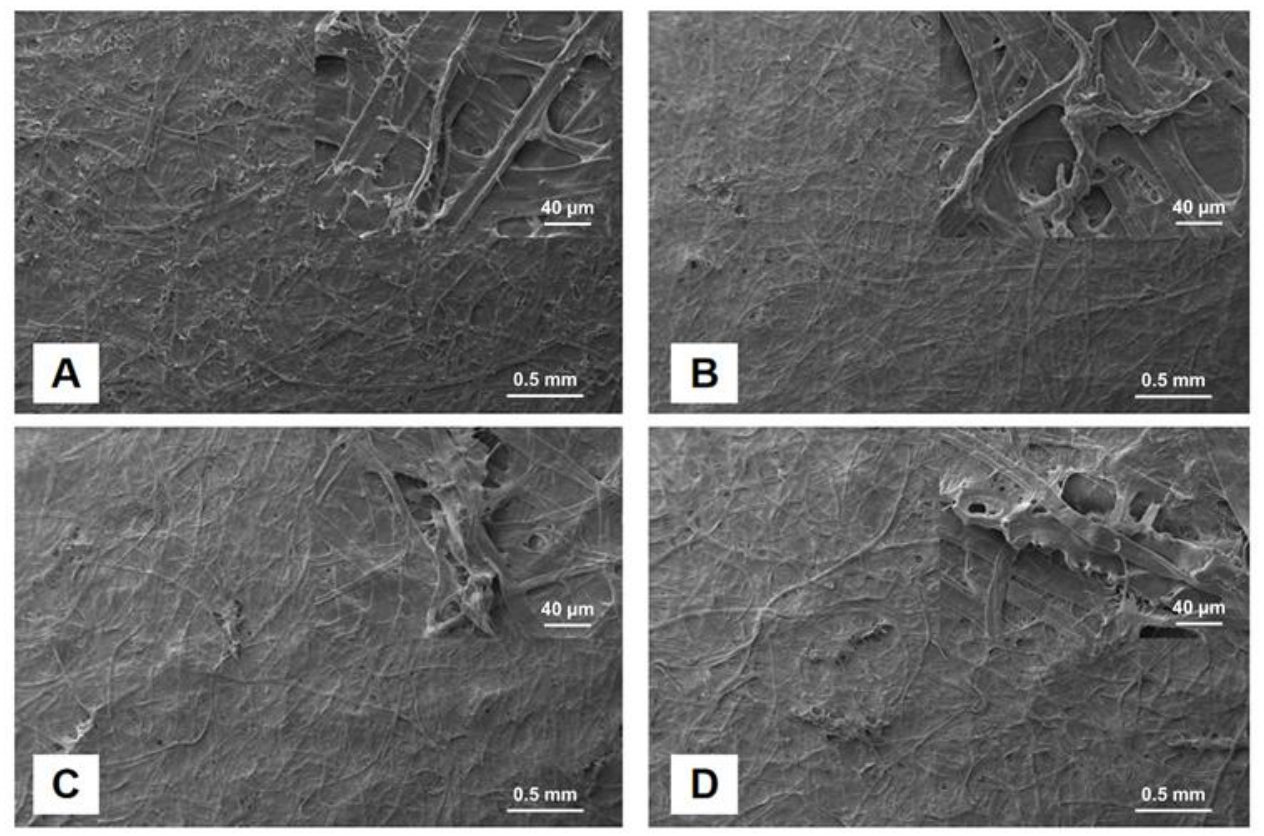

Fig. 2. SEM microstructures of (a) PSP, (b) EP- $\mathrm{H}_{2} \mathrm{O}-10 \%$, (c) $\mathrm{EP}-\mathrm{NaOH}-10 \%$, and (d) $\mathrm{EP}-\mathrm{H}_{2} \mathrm{SO}_{4}-$ $10 \%$

Surface roughness is one of the predominant factors affecting the hydrophobicity (Yang et al. 2017). The hydrophobicity of the handsheets made from $\mathrm{EP}-\mathrm{H}_{2} \mathrm{O}$ and softwood pulps was characterized by measuring the water contact angle, and the results are presented in Fig. 4. The EP- $\mathrm{H}_{2} \mathrm{O}-70 \%$ had the highest contact angle $\left(83.8^{\circ}\right)$, while the contact angle of PSP was $58.8^{\circ}$. The increased contact angle revealed that the handsheets were not easily wetted by water and might result in high hydrophobicity (Fig. 4). Hydrophobic cellulosic materials were always in high demand in industrial applications regarding food packaging, sanitation, fabrics, etc. (Sobhana et al. 2017). Therefore, the handsheets made with softwood pulp and exploded COS pulp could have a huge potential application. 



Fig. 3. SEM micrstructures and $3 D$ surface topographies of (a) PSP and (b through h) composite handsheets made from EP- $\mathrm{H}_{2} \mathrm{O}$ and softwood pulp
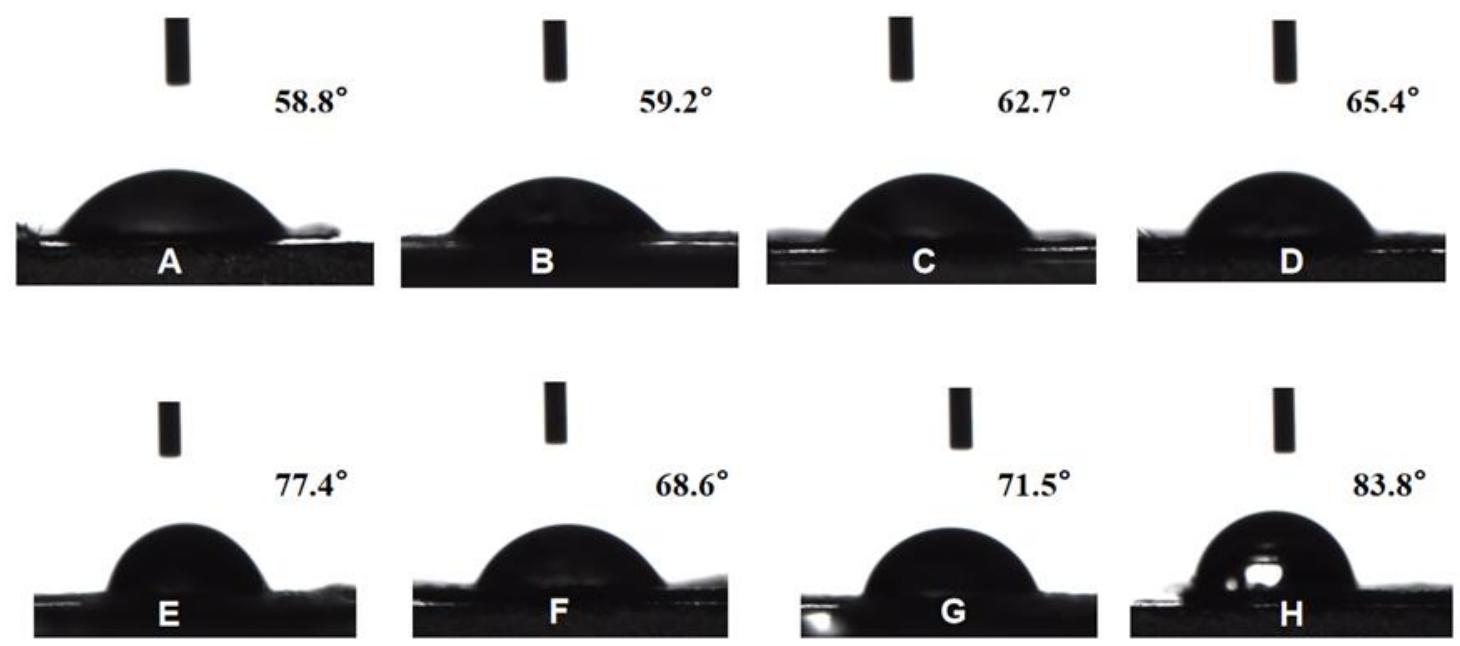

Fig. 4. The contact angles of (a) PSP and (b through $h$ ) handsheets made from $E P-\mathrm{H}_{2} \mathrm{O}$ and softwood pulps

The whiteness values of the handsheets are presented in Table 4, where it is shown that the addition of EP played an import role in changing the whiteness of the handsheets. When the proportion of the steam-exploded COS pulps was $70 \%$, the values of whiteness 
for $\mathrm{EP}-\mathrm{H}_{2} \mathrm{O}-70 \%$, $\mathrm{EP}-\mathrm{NaOH}-70 \%$, and $\mathrm{EP}-\mathrm{H}_{2} \mathrm{SO}_{4}-70 \%$ were only $11.1 \%, 9.5 \%$, and $10.2 \%$, respectively (Table 4). However, the whiteness of PSP was $72.1 \%$ when no exploded fibers were added (Table 4). After steam explosion, the obtained COS fibers were brown. The handsheets with steam-exploded COS fibers had a strong absorption of light, resulting in the increase of the absorption coefficient and the decrease of the scattering coefficient.

Table 4 shows that the parameter $L^{*}$ of the handsheets decreased when the proportion of steam-exploded COS pulps increased. The increased values of $a^{*}$ and $b^{*}$ indicated that the handsheets were more green and yellow (Cruz et al. 2007). The parameters $a^{*}$ and $b^{*}$ of $\mathrm{EP}-\mathrm{NaOH}-\mathrm{Y} \%$ and $\mathrm{EP}-\mathrm{H}_{2} \mathrm{SO}_{4}-\mathrm{Y} \%$ were generally higher than those of $\mathrm{EP}-\mathrm{H}_{2} \mathrm{O}-\mathrm{Y} \%$, indicating that the handsheets made from softwood pulps and EP$\mathrm{H}_{2} \mathrm{O}$ were less green and yellow. The increased values of $\Delta E^{*}$ revealed that greater color changes were observed when the proportion of steam-exploded COS pulps increased.

Table 4. Chroma Parameters of the Steam-exploded COS Pulp-based Handsheets

\begin{tabular}{|c|c|c|c|c|c|c|c|c|}
\hline \multicolumn{2}{|c|}{ Samples } & $L^{*}$ & $a^{*}$ & $b^{*}$ & $\Delta E^{*}$ & $L^{n}$ & $a^{n}$ & $b^{n}$ \\
\hline \multicolumn{2}{|c|}{$\mathrm{PSP}$ * } & 88.85 & 0.34 & 1.54 & 0 & 1 & 1 & 1 \\
\hline \multirow{7}{*}{$\mathrm{EP}-\mathrm{H}_{2} \mathrm{O}-$} & $10 \%$ & 75.33 & 1.59 & 4.48 & 13.89 & 0.85 & 4.68 & 2.91 \\
\hline & $20 \%$ & 69.23 & 2.20 & 5.70 & 20.14 & 0.78 & 6.47 & 3.70 \\
\hline & $30 \%$ & 63.61 & 2.56 & 6.51 & 25.82 & 0.72 & 7.53 & 4.23 \\
\hline & $40 \%$ & 58.62 & 3.05 & 7.58 & 30.94 & 0.66 & 8.97 & 4.92 \\
\hline & $50 \%$ & 52.83 & 3.64 & 8.99 & 36.93 & 0.59 & 10.71 & 5.84 \\
\hline & $60 \%$ & 49.76 & 3.98 & 9.68 & 40.09 & 0.56 & 11.71 & 6.29 \\
\hline & $70 \%$ & 45.77 & 4.43 & 10.76 & 44.25 & 0.52 & 13.03 & 6.99 \\
\hline \multirow{7}{*}{ EP-NaOH- } & $10 \%$ & 82.47 & 1.4 & 4.72 & 7.21 & 0.93 & 4.12 & 3.06 \\
\hline & $20 \%$ & 70.97 & 2.35 & 6.62 & 18.64 & 0.80 & 6.91 & 4.17 \\
\hline & $30 \%$ & 67.45 & 2.76 & 7.29 & 22.29 & 0.76 & 8.12 & 4.73 \\
\hline & $40 \%$ & 53.07 & 3.79 & 9.11 & 36.73 & 0.60 & 11.15 & 5.92 \\
\hline & $50 \%$ & 50.03 & 3.99 & 9.42 & 39.78 & 0.56 & 11.74 & 6.12 \\
\hline & $60 \%$ & 44.25 & 4.47 & 10.24 & 45.43 & 0.50 & 13.15 & 6.65 \\
\hline & $70 \%$ & 42.81 & 4.68 & 10.5 & 47.10 & 0.48 & 13.76 & 6.82 \\
\hline \multirow{7}{*}{$\mathrm{EP}-\mathrm{H}_{2} \mathrm{SO}_{4}-$} & $10 \%$ & 78.60 & 1.46 & 4.43 & 10.70 & 0.88 & 4.29 & 2.88 \\
\hline & $20 \%$ & 72.10 & 2.21 & 6.13 & 17.47 & 0.81 & 6.50 & 3.98 \\
\hline & $30 \%$ & 65.32 & 2.72 & 7.25 & 24.33 & 0.74 & 8.00 & 4.71 \\
\hline & $40 \%$ & 60.62 & 3.20 & 8.34 & 29.18 & 0.68 & 9.41 & 5.42 \\
\hline & $50 \%$ & 51.94 & 4.01 & 10.13 & 38.07 & 0.58 & 11.76 & 6.58 \\
\hline & $60 \%$ & 47.97 & 4.34 & 10.70 & 42.08 & 0.54 & 12.76 & 6.96 \\
\hline & $70 \%$ & 44.49 & 4.71 & 11.32 & 45.64 & 0.50 & 13.85 & 7.35 \\
\hline
\end{tabular}

It was noteworthy that the properties of the handsheets were seriously affected by the addition of the steam-exploded COS pulps (Tables 3 and 4). Different impregnation treatments of COS hardly caused the properties of the handsheets to change (Tables 3 and 4). This was probably because there were no obvious structural differences in the steamexploded COS fibers when impregnated by three methods. Hence, from the perspective of economic and environmental protection, the COS could be impregnated with water before the steam explosion, and then used in the papermaking industry. In conclusion, the COS could be successfully deconstructed by steam explosion, and a combination of water impregnation and steam explosion was a good pulp process for COS. 


\section{CONCLUSIONS}

1. The combination of impregnation treatment and steam explosion was effective for deconstructing Camellia oleifera shell (COS) to make fibers and bundles.

2. The hemicellulose of COS degraded severely during the acid impregnation process, while lignin was mostly removed in the alkali impregnation treatment.

3. The results showed that the whiteness and tensile index of the handsheets declined when the addition of exploded-steam COS pulps increased, while the roughness, hydrophobicity, and air permeability became enhanced. However, the types of impregnation treatments slightly affected the properties of the steam-exploded COS fibers. From the perspective of economic and environmental protection, COS could be impregnated with water before steam explosion. This study indicated that COS was a good material for the papermaking industry, and a combination of water impregnation and steam explosion treatment was an efficient pulp process.

\section{ACKNOWLEDGEMENTS}

The work was supported by the National Natural Science Foundation of China (31971603), The Project Supported by the Foundation of Guangxi Key Laboratory of Clean Pulp and Papermaking and Pollution Control (No. 2019KF06), College of Light Industry and Food Engineering, Guangxi University, the Fundamental Research Funds for the Central Universities (2019MS084), and the Foundation of State Key Laboratory of Biobased Material and Green Papermaking (No. KF201802). The authors would like to give their appreciation to Dr. Shengdan Wang and Ms. Haocheng Fu for their assistance with the experiments.

\section{REFERENCES CITED}

Carvalho, A. F. A., Marcondes, W. F., Neto, P. O., Pastore, G. M., Saddler, J. N., and Arantes, V. (2018). "The potential of tailoring the conditions of steam explosion to produce xylo-oligosaccharides from sugarcane bagasse," Bioresource Technology 250, 221-229. DOI: 10.1016/j.biortech.2017.11.041

Cruz, R. M. S., Vieira, M. C., and Silva, C. L. M. (2007). "Modelling kinetics of watercress (Nasturtium officinale) colour changes due to heat and thermosonication treatments," Innovative Food Science \& Emerging Technologies 8(2), 244-252. DOI: 10.1016/j.ifset.2007.01.003

Dong, Z., Hou, X., Sun, F., Zhang, L., and Yang, Y. (2014). "Textile grade long natural cellulose fibers from bark of cotton stalks using steam explosion as a pretreatment," Cellulose 21, 3851-3860. DOI: 10.1007/s10570-014-0401-5

Duangwang, S., Ruengpeerakul, T., Cheirsilp, B., Yamsaengsung, R., and Sangwichien, C. (2016). "Pilot-scale steam explosion for xylose production from oil palm empty fruit bunches and the use of xylose for ethanol production," Bioresource Technology 203, 252-258. DOI: 10.1016/j.biortech.2015.12.065

Han, Y., Xu, J., Zhao, Z., and Zhao, J. (2018). "Analysis of enzymolysis process kinetics and estimation of the resource conversion efficiency to corn cobs with alkali soaking, 
water and acid steam explosion pretreatments," Bioresource Technology 264, 391394. DOI: 10.1016/j.biortech.2018.06.045

Iram, A., Cekmecelioglu, D., and Demirci, A. (2019). “Optimization of dilute sulfuric acid, aqueous ammonia, and steam explosion as the pretreatments steps for distillers' dried grains with solubles as a potential fermentation feedstock," Bioresource Technology 282, 475-481. DOI: 10.1016/j.biortech.2019.03.009

ISO 5267-1: 1999 (E). "Pulps - Determination of drainability - Part1: Schopper-Riegler method,"

ISO 5269-2: 2004. "Pulps - Preparation of laboratory sheets for physical testing - Part 2: Rapid - Köthen method,"

Kataria, R., Mol, A., Schulten, E., Happel, A., and Mussatto, S. I. (2017). "Bench scale steam explosion pretreatment of acid impregnated elephant grass biomass and its impacts on biomass composition, structure and hydrolysis," Industrial Crops and Products 106, 48-58. DOI: 10.1016/j.indcrop.2016.08.050

Lei, Z., Wang, S., Fu, H., Gao, W., Wang, B., Zeng, J., and Xu, J. (2019). “Thermal pyrolysis characteristics and kinetics of hemicellulose isolated from Camellia oleifera shell," Bioresource Technology 282, 228-235. DOI: 10.1016/j.biortech.2019.02.131

Neves, P. V., Pitarelo, A. P., and Ramos, L. P. (2016). "Production of cellulosic ethanol from sugarcane bagasse by steam explosion: Effect of extractives content, acid catalysis and different fermentation technologies," Bioresource Technology 208, 184194. DOI: 10.1016/j.biortech.2016.02.085

Nong, G., Li, P., Li, Y., Xing, D., Zhu, T., Wu, J., Gan, W., Wang, S., and Yin, Y. (2019). "Preparing tea filter papers with high air permeability from jute fibers for fast leaching," Industrial Crops and Products 140, Article ID 111619. DOI: 10.1016/j.indcrop.2019.111619

Pasangulapati, V., Ramachandriya, K. D., Kumar, A., Wilkins, M. R., Jones, C. L., and Huhnke, R. L. (2012). "Effects of cellulose, hemicellulose and lignin on thermochemical conversion characteristics of the selected biomass," Bioresource Technology 114, 663-669. DOI: 10.1016/j.biortech.2012.03.036

Resa, C. P. O., Jagus, R. J., and Gerschenson, L. N. (2014). "Effect of natamycin, nisin and glycerol on the physicochemical properties, roughness and hydrophobicity of tapioca starch edible films," Materials Science and Engineering: C 40, 281-287. DOI: 10.1016/j.msec.2014.04.005

Santo, M. C. E., Cardoso, E. B., Guimaraes, F. E. G., deAzevedo, E. R., da Cunha, G. P., Novotny, E. H., Pellegrini, V. O. A., Chandel, A. K., Silveria, M. H. L., and Polikarpov, I. (2019). "Multifaceted characterization of sugarcane bagasse under different steam explosion severity conditions leading to distinct enzymatic hydrolysis yields," Industrial Crops and Products 139, Article ID 111542. DOI: 10.1016/j.indcrop.2019.111542

Sannigrahi, P., Ragauskas, A. J., and Miller, S. J. (2008). "Effects of two-stage dilute acid pretreatment on the structure and composition of lignin and cellulose in loblolly pine," Bioenergy Research 1(3-4), 205-214. DOI: 10.1007/s12155-008-9021-y

Sabiha-Hanim, S., Noor, M. A. M., and Rosma, A. (2015). "Fractionation of oil palm frond hemicelluloses by water or alkaline impregnation and steam explosion," Carbohydrate Polymers 115, 533-539. DOI: 10.1016/j.carbpol.2014.08.087

Sui, W., and Chen, H. (2016). "Effects of water states on steam explosion of lignocellulosic biomass,” Bioresource Technology 199, 155-163. DOI: 10.1016/j.biortech.2015.09.001 
Sibaly, S., and Jeetah, P. (2017). "Production of paper from pineapple leaves," Journal of Environmental Chem. Engineering 5(6), 5978-5986. DOI: 10.1016/j.jece.2017.11.026

Sobhana, S. S. L., Zhang, X., Kesavan, L., Liias, P., and Fardim, P. (2017). "Layered double hydroxide interfaced stearic acid - Cellulose fibres: A new class of superhydrophobic hybrid materials," Colloids and Surfaces A: Physicochemical and Engineering Aspects 522, 416-424. DOI: 10.1016/j.colsurfa.2017.03.025

Song, Y., Jiang, W., Zhang, Y., Ben, H., Han, G., and Ragauskas, A. J. (2018). "Isolation and characterization of cellulosic fibers from kenaf bast using steam explosion and Fenton oxidation treatment," Cellulose 25(9), 4979-4992. DOI: 10.1007/s10570-0181916-y

Shi, Q., Li, Y., Li, Y., Cheng, Y., and Zhu, W. (2019). "Effects of steam explosion on lignocellulosic degradation of, and methane production from, corn stover by a cocultured anaerobic fungus and methanogen," Bioresource Technology 290, Article ID 121796. DOI: 10.1016/j.biortech.2019.121796

TAPPI T248 sp-00 (2000). "Laboratory beating of pulp (PFI mill method)," TAPPI Press, Atlanta, GA, USA.

TAPPI T494 om-01 (2001). "Tensile properties of paper and paperboard," TAPPI Press, Atlanta, GA, USA.

TAPPI T562 pm-96 (1996). "CIE whiteness and tint of paper and paperboard (using $45^{\circ} / 0^{\circ}$ directional illumination and normal viewing)," TAPPI Press, Atlanta, GA, USA.

Xiang, Z., Watson, J., Tobimatsu, Y., and Runge, T. (2014). "Film-forming polymers from distillers' grains: Structural and material properties," Industrial Crops and Products 59, 282-289. DOI: 10.1016/j.indcrop.2014.05.023

Yao, J., Huang, H., Mao, L., Li, Z., Zhu, H., and Liu, Y. (2017). "Structural and optical properties of cellulose nanocrystals isolated from the fruit shell of Camellia oleifera Abel," Fibers and Polymers 18(11), 2118-2124. DOI: 10.1007/s 12221-017-7489-9

Yamamoto, Y., Ichiura, H., and Ohtani, Y. (2019). "Improvement of wet paper strength using a phosphoric acid-urea solution," Cellulose 26, 5105-5116. DOI:

10.1007/s10570-019-02423-y

Yiin, C. L., Ho, S., Yusup, S., Quitain, A. T., Chan, Y. H., Loy, A. C. M., and Gwee, Y. L. (2019). "Recovery of cellulose fibers from oil palm empty fruit bunch for pulp and paper using green delignification approach," Bioresource Technology 290, Article ID 121797. DOI: 10.1016/j.biortech.2019.121797

Yu, J., Zhu, Y., Ma, H., Liu, L., Hu, Y., Xu, J., Wang, Z., and Fan, Y. (2019). "Contribution of hemicellulose to cellulose nanofiber-based nanocomposite films with enhanced strength, flexibility and UV-blocking properties," Cellulose 26, 60236034. DOI: 10.1007/s10570-019-02518-6

Zhu, J., Zhu, Y., Jiang, F., Xu, Y., Jia, O., Yu, S.Y. (2013). “An integrated process to produce ethanol, vanillin, and xylooligosaccharides from Camellia oleifera shell." Carbohydrate Research 382, 52-57. DOI:10.1016/j.carres.2013.10.007

Article submitted: September 23, 2020; Peer review completed: December 5, 2020; Revised version received and accepted: March 10, 2021; Published: April 5, 2021.

DOI: 10.15376/biores.16.2.3734-3745 